Research Article

\title{
Vibration Fracture Mechanism and Optimization Design of Array Power Supply for Near-Space SAR
}

\author{
Changrui Wang $\mathbb{D},{ }^{1}$ Lina Tang $\mathbb{D}^{2},{ }^{2}$ and Henghai Wang $\mathbb{D}^{3}$ \\ ${ }^{1}$ National Key Laboratory of Science and Technology on Helicopter Transmission, \\ Nanjing University of Aeronautics and Astronautics, Nanjing 210016, China \\ ${ }^{2}$ Shanghai Aerospace Equipments Manufacturer Co., Ltd., Shanghai 200245, China \\ ${ }^{3}$ The 14th Research Institute of China Electronics Technology Group Corporation, Nanjing 210039, China \\ Correspondence should be addressed to Changrui Wang; wchrui2016@163.com
}

Received 19 September 2019; Revised 27 December 2019; Accepted 30 December 2019; Published 1 February 2020

Academic Editor: Giuseppe Ruta

Copyright (c) 2020 Changrui Wang et al. This is an open access article distributed under the Creative Commons Attribution License, which permits unrestricted use, distribution, and reproduction in any medium, provided the original work is properly cited.

\begin{abstract}
The random vibration failure of an array power supply for near-space SAR was analyzed. The fracture mechanism and the fracture reason of fracture formation in the specimen were investigated. The results show that antishock MOS pin breaks first, and the power supply is still in the working state during the process of random vibration. This caused dischargings at the tip of the fracture and melting of the tip of the broken pin which form a river-shaped fracture and granular tissue. The plastic fracture with typical dimple morphology of the pins for the resistor tube occurred during the random vibration. The intergranular fracture appeared at the welding part of the electronic components for array power supply, which presented a brittle fracture mechanism. The fracture was dominated by a ductile fracture for components when the stress produced by the vibration was close to the yield strength of the material. The fracture was dominated by a brittle fracture for components when the stress produced by the vibration was far beyond the yield strength of the material. A simulation evaluation system based on the high-confidence model was proposed. The stress of the electronic components for array power supply and its welding was much lower than the allowable strength of the material by the optimization of the structure and the form of the welding for the array power supply. The sample was successfully tested and verified without any further fracture problems.
\end{abstract}

\section{Introduction}

There is no influence of meteorological cloud and rain and also the air flow is stable in the near-space airspace $(20-100 \mathrm{~km}$ above the Earth) which is conducive to the movement of high-speed aircraft and floating slow platform [1-3]. Therefore, with the advantages of higher mobility, shorter preparation period, stronger penetration ability, and richer task modes, near-space vehicles can be used for dynamic observations in specific regions of the world for the purpose of terrestrial environment and disaster monitoring, large-area security surveillance, real-time battlefield monitoring, and accurate strikes [4-7]. Near-space synthetic aperture radar (SAR) is the "eyes" of near-space vehicles for the communication, detection, and guidance functions, and its research is still in the theoretical stage [8]. At present, research studies on near-space SAR focus on large-scale SAR scenes, high-resolution imaging, and slow-target SAR moving target detection and imaging modes as well as algorithms [9-13].

As a core component of the near-space SAR, the array power supply is different from the traditional centralized high-power and high-voltage form, which generally adopts the high-power density form of low voltage and high current. Array power supply experiences harsh vibrations during the take-off, cruise, and landing of an aircraft whose performance is related to the operational reliability of the SAR [14-16]. The array power supply needs to be reasonably distributed in a limited space and needs to maintain the working stability in a bad working environment. So the 
reasonable structure design is particularly important. However, near-space vehicles often face a complicated working environment and the vibrations in each process will cause great harm to the module-level devices in the SAR. When designing and using an array power supply, random vibration failure is an essential consideration [17-19]. There are currently few studies which consider random vibration fatigue of array power supply.

The most obvious characteristic of random vibration is nonperiodic. In recent years, considerable efforts have been focused on the aspects of theoretical model, experiment, simulation, and shock absorption for the random vibration [20-23]. On the theoretical side, Dzenis and Saunders [24] set up a mathematical model which can be used for the development of mechanism-based predictive models of fracture and life. Zhang and Qiao [25] proposed a new model to quantitatively analyze the fracture behavior of materials in which validity was also verified. Jiang et al. [26] deduced the analytic formulation of dynamic response bounds for both the linear single degree of freedom (SDOF) vibration system and the multiple degree of freedom (MDOF) vibration system which can provide theoretical help for the follow-up research of random vibration analysis. Chen et al. [27] proposed a novel method for random vibration analysis of single degree of freedom (SDOF) vibroimpact systems which can be used as the benchmark to examine the accuracy of approximate solutions obtained by other methods. In order to reduce the cost and shorten the test period, random vibration qualification tests performed in a laboratory will typically be run using much higher acceleration levels than the values found in the actual environments which are often considered to be accelerated life tests. Gharaibeh and Pitarresi [28] employed the Taguchi method for random vibration analysis to investigate the fatigue life performance of electronic vehicles and gave an optimal design for the best fatigue performance. With the aim of investigating effects of both Gaussian and non-Gaussian random excitation on the vibration fatigue, Jiang et al. [29] explored a novel accelerated random vibration fatigue test methodology and strategy. Liu et al. [30] used the frequency-domained method to analyze the random vibration fatigue of airborne structural components and proposed a scheme for design improvement by simulations. Pothula et al. [31] studied the fatigue failure of the accelerated random vibration test which was compared with the theoretical model. It was pointed out that the exponent is related to all theories for undamped beams and in general with Dirlik theory for damped beams. Through vibration failure analysis, the mechanical behavior and failure laws of a material can be found out, which provides reference for design and simulation evaluation $[32,33]$. Furthermore, the method of establishing a failure and simulation evaluation system for electronic devices in near space is a very important research topic. Lu et al. [34] applied the precise integration method (PIM) to study nonstationary random vibration of structures subjected to moving loads and got an excellent result. Zeng et al. [35] used the finite element method and pseudoexcitation method to simulate the vertical random vibration of the interaction system of the vehicle slab track ridge and verified the reliability and efficiency of the simulation method. Li et al. [36] established an aircraft model, the finite element method-boundary element method of dynamic model (FEM-BEM dynamic model) to predict the characteristics of the vibration-acoustic coupling. In order to avoid the influence of random vibration on the equipment, many scholars have studied the shock absorption of random vibration. Wang et al. [37] and $\mathrm{Li}$ et al. [38] studied the variable frequency vibration isolators and dynamic antiresonance isolators in order to reduce the damage of vibration to airborne products. Dong et al. [39] had put forward a dynamic equation of the coupled system resulting in the remarkable vibration attenuation for the primary system and a larger bandwidth for vibration absorption. Harmoko et al. [40] designed an effective vibration isolation system based on military specifications MIL-STD-810E which ensured that the equipment can work smoothly and normally under random vibration load. Although scholars have conducted many research studies on the random vibration of the equipment, there are few research studies on the power supply of near-space SAR from the perspective of the three-dimensional integration of theory, simulation, and experiment. And the relevant research studies are of great significance and value for near-space vehicles.

Therefore, the theory and vibration failure of array power supply for a near-space SAR are analyzed in this paper. The fracture mechanism and the reason for its formation in the specimen were investigated. Three-dimensional integration methods of structure optimization-digital simulation-test verification are used to solve the failure of the array power supply device. The simulation evaluation system based on a high-confidence model is also proposed and verified.

\section{Theoretical Analysis and Experiment Method of Random Vibration}

2.1. Theoretical Analysis of Random Vibration. Mode is the inherent property of the structure for electronic systems. The natural frequency, mode shape, and other modal parameters of the structure can be obtained by calculation or test analysis. Modal analysis is the premise of the random vibration test and simulation analysis. It is widely used to obtain modal parameters (natural frequency, mode shape, and damping) through the modal test to modify the finite element model. Therefore, in order to decouple the structure of electronic equipment, it is necessary to analyze the natural frequencies and modes of vibration before random vibration analysis. The random vibration test is generally conducted separately in three directions. The random vibration equations in all directions are the same. Taking the random vibration in the $X$ direction as an example, the dynamic equation of the array power supply is $[41,42]$

$$
M \ddot{x}+C \dot{x}+K x=F(t),
$$

where $M, C$, and $K$ are the mass matrix, damping matrix, and stiffness matrix of the multidegree of freedom system, respectively, $\ddot{x}, \dot{x}$, and $x$ are the acceleration, velocity, and 
displacement vector, and and $F(t)$ is the excitation vector of the fixture.

When studying the modes of random vibration for electronic systems, the electronic equipment is directly fixed on the test fixture, which is considered as a fixed connection. It is generally believed that $F(t)=0$ and $C=0$. Therefore, equation (1) can be simplified to the dynamic equation of an undamped free vibration system:

$$
M \ddot{x}+K x=0 .
$$

Let $x=A \sin (\omega t)$, where $A$ is the amplitude. Combined with equation (2), we can obtain the following equation:

$$
K-\omega_{i}^{2} M=0,
$$

where $\omega_{i}$ is the $i$ th circular frequency of the system and $f_{i}=\omega_{i} / 2 \pi$ is the $i$ th natural frequency.

The modes of random vibration can also be estimated using a polynomial series [43]:

$$
f_{i}=\frac{\omega_{i}}{2 \pi}=\frac{5.31}{\pi}\left[\frac{D}{\rho}\left(\frac{1}{15 c^{4}}+\frac{1}{9 c^{2} d^{2}}+\frac{1}{15 d^{4}}\right)\right],
$$

where $\rho=W / a b g=u h / g$ (mass per unit area), $W$ is the total weight of plate, $u$ is the material density, $a$ is the length of plate, $b$ is the width of plate, $h$ is the plate thickness, and $g$ is the acceleration of gravity.

This is also the theoretical basis for modal test and simulation. Compared with the natural frequency of the test mode, the response surface method can be used to modify the finite element model of power supply, and the dynamic characteristics of the modified finite element model of power supply are predicted and evaluated. Generally speaking, the reliability of the simulation results of modes is quite high, which can be directly followed by the subsequent random vibration analysis as long as the simplification of the model and the boundary design are reasonable.

The most common method used for evaluating random vibration is in terms of the power spectral density (PSD). According to the type or condition of the environment that the curve attempts to simulate, the random vibration input PSD curve can have many shapes. The more common types of curves are shown in Figure 1. The square root of the area under the curve still represents the input acceleration level. The input acceleration level is calculated by the curve area. When the slope is not $-3 \mathrm{~dB}$, the following formula can be used to determine the area under the positive or negative slope sections:

$$
\begin{aligned}
A & =\frac{3 P_{2}}{3+S}\left[f_{2}-\left(\frac{f_{1}}{f_{2}}\right)^{S / 3} f_{1}\right], \\
\text { or } A & =\frac{3 P_{2}}{3+S}\left[\left(\frac{f_{2}}{f_{1}}\right)^{S / 3} f_{2}-f_{1}\right],
\end{aligned}
$$

where $P_{1}$ and $P_{2}$ are the input PSD at the resonant frequency $\left(\mathrm{g}^{2} / \mathrm{Hz}\right), f_{1}$ and $f_{2}$ are the corresponding frequency, and $S$ is the slope of curve. When the sloped section of the PSD curve

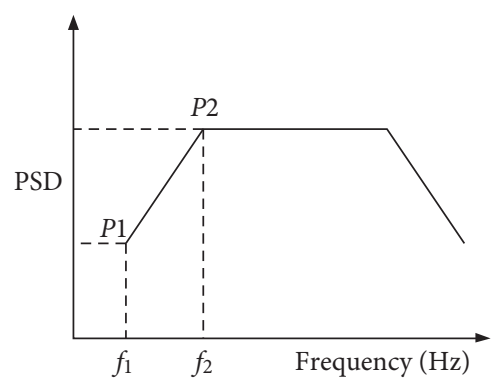

FIgURE 1: Typical random vibration input PSD curves.

has a value of $-3 \mathrm{~dB}$, the area under the curve can be found by using the following equations:

$$
A=-f_{2} P_{2} \log _{e} \frac{f_{2}}{f_{1}} .
$$

The area under the flat-top section, where the slope is zero can be determined from the following relation:

$$
A=P\left(f_{2}-f_{1}\right) \text {. }
$$

According to formulas (5)-(8), the input value of the random vibration test according to the actual test curve in Section 2.2 can be calculated.

In the random vibration experiment, the vibration is generally carried out along a certain axis. After the end of the test, the other two axial vibrations shall be carried out, respectively. Therefore, electronic equipment can be defined as a single degree of freedom system in the random vibration test and simulation. The system response caused by vibration at the resonant frequency will change with the magnitude of the varying displacement. It is necessary to obtain the response of the electronic equipment to a random vibration input. This is usually achieved by using the following equation [43]:

$$
P_{\text {out }}=Q^{2} P,
$$

where $P$ is the input PSD at the resonant frequency $\left(\mathrm{g}^{2} / \mathrm{Hz}\right)$, $Q$ is the transmission rate, and $P_{\text {out }}$ is the response of the test module.

$$
Q=\left[\frac{1+\left(2 R_{\Omega} R_{c}\right)^{2}}{\left(1-R_{\Omega}^{2}\right)^{2}+\left(2 R_{c} R_{\Omega}\right)^{2}}\right]^{1 / 2},
$$

where $R_{\Omega}$ is the ratio of the resonant frequency $(f)$ to the natural frequency $\left(f_{i}\right)$ and $R_{C}$ is the damping ratio. The response of the module in case of random vibration is

$$
G_{\text {out }}^{2}=\int_{0}^{\infty} \frac{P \mathrm{~d} f}{\left[1-\left(f / f_{i}\right)^{2}\right]^{2}+2 R_{c}\left(f / f_{i}\right)^{2}}
$$

The above equation can be integrated to obtain the mean square acceleration response of the mass to the random vibration input:

$$
G_{\text {out }}=\frac{2 \pi f_{n} P}{8 R_{c}} .
$$


In a light-damped system, the relation between the damping ratio and transmission rate can be expressed by

$$
R_{c}=\frac{1}{2 Q} \text {. }
$$

Therefore, equation (12) can be written as

$$
G_{\text {out }}=\sqrt{\frac{\pi}{2} P f_{n} Q}
$$

The calculation and simulation error are very small when the slope within the resonant frequency range is less than $6 \mathrm{~dB} /$ oct. According to this theoretical model, the random vibration test and simulation optimization analysis of power supply are carried out.

2.2. Test Method. The vibration tests of the array power supply before and after structure design optimization are conducted on a V3000-26 vibrating table, and the test duration is $5 \mathrm{~min}$ in each axial direction (three axial directions in total), as shown in Figure 2. The functional vibration test is carried out according to the broadband random test method, as shown in Figure 3. The frequency set in the test is $5-2000 \mathrm{~Hz}$. The square root of the area under the curve still represents the input RMS acceleration level. Calculating according to formulas (5)-(8), $A 1=0.6 \mathrm{~g}^{2}, A 2=0.0033 \mathrm{~g}^{2}, A 3=28 \mathrm{~g}^{2}, A 4=80 \mathrm{~g}^{2}$, and the total area under the curve leads to the RMS acceleration: $A=A 1+A 2+A 3+A 4=108.6033 \mathrm{~g}^{2}$.

The array power supply (Figure 4 ) is fixed on the test bench by means of a fixture so that the test piece is axially stressed. An internal view of the array power supply is shown in Figure 5. The rectangular PCB is the most common shape used by the electronics industry since this shape is easily adapted to the popular modular plug-in type of assembly, which utilizes an electrical connector along the bottom edge of the circuit board (Figure 5). The high-power semiconductor tubes are fixed to the PCB first, and then to the power supply shell. In order to ensure the heat dissipation of the device, one side of the device shall be close to the shell of array power supply. Ribs are often added to PCBs shell which increase the stiffness of the circuit board and increases the resonant frequency. The PCB board is fixed to the power supply shell with screws.

During the test, no less than 3 control points are arranged at the connection points between the array power supply and the fixture to avoid the amplification of the input response transmitted to the array power supply through the fixture. The locations of test points are determined by evaluating the risk points. Observations are performed by a SMZ10 00 stereo microscope and 4300 scanning electron microscope which is used for SEM and EDS analysis.

\subsection{Simulation Evaluation System Based on High-Confidence} Model. The fundamental nature of random vibration and fatigue should be studied deeply in order to design, develop, and produce cost-effective and lightweight structures with a high degree of reliability. The load-carrying capability of the structural elements is also examined by the

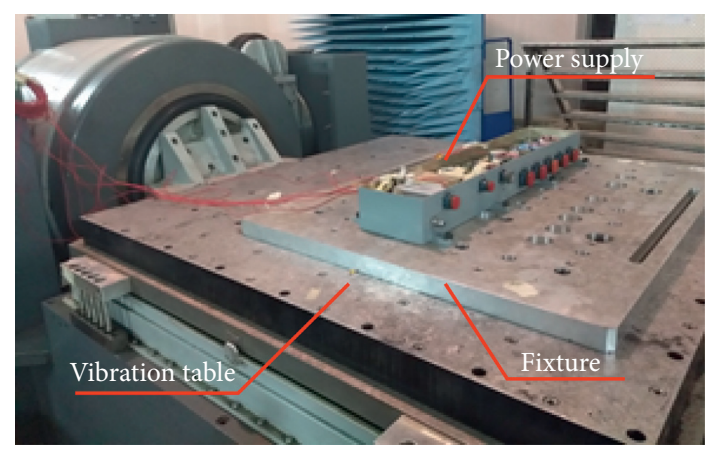

FIGURE 2: The vibration test site.

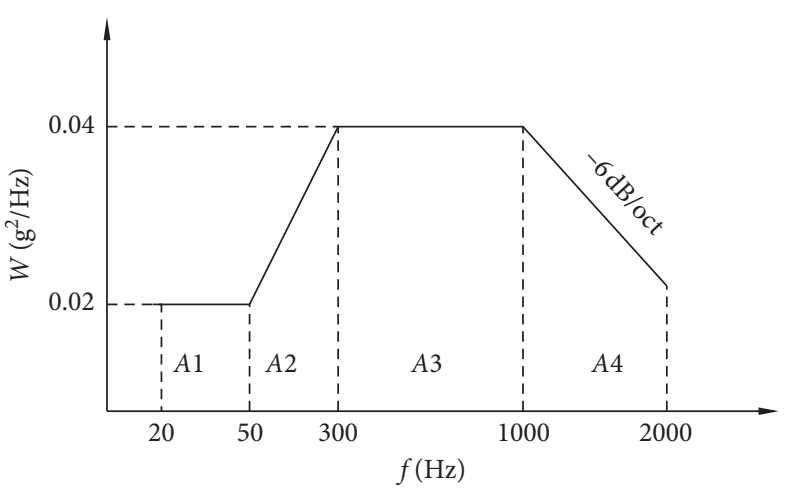

Figure 3: Functional test vibration spectrum.

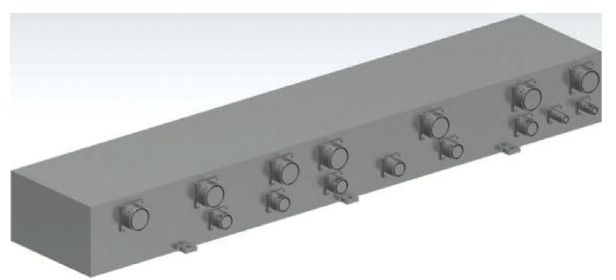

FIgURE 4: The schematic diagram of external for array power supply.

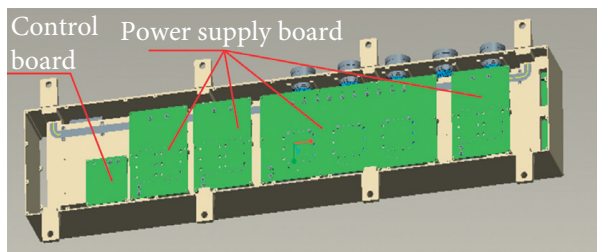

FIgURE 5: The schematic diagram of internal for array power supply.

accelerated test and simulation to make sure it does not buckles under the expected dynamic loads. In view of the frequent fracture failure of electronic equipment, the simulation evaluation system based on the high-confidence model is proposed. The specific implementation process is as follows (Figure 6): Firstly, the random vibration acceleration experiment of the first designed power supply is carried out. In case of fracture failure of electronic components, the causes of failure are analyzed and solutions are 


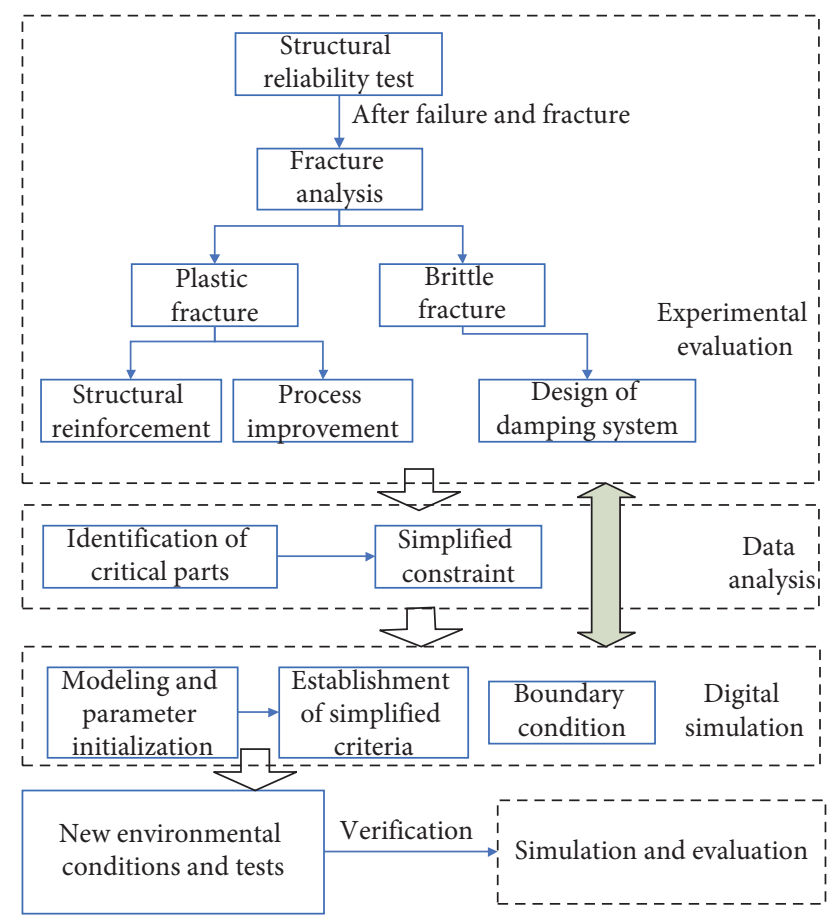

FIGURE 6: Flow chart of the simulation evaluation system based on the high-confidence model.

given according to the causes. Then, according to the cause analysis, the power supply is optimized. Based on the above fracture analysis and design optimization, the simulation research is carried out. In order to ensure the accuracy of simulation, a large number of experiments are carried out to modify the simulation model and boundary conditions to improve the simulation accuracy and the simulation results are compared with the experiments again to determine the accuracy of the simulation. Finally, the proposed simulation evaluation system based on the highconfidence model is used to directly simulate the vibration of the follow-up new power supply, reduce the tests, and shorten the research and development period.

\section{Test Results and Discussions}

3.1. Test Phenomenon Description. Firstly, the random vibration acceleration experiment was carried out for the original design power supply. In the process of random vibration test, it was found that the radar display console showed a power supply failure. An examination of the array power supply showed that the three pins of the antishock MOS tube on the back of the power input processing module were all broken near the tube body and a pin of the antishock resistor was broken, as shown in Figure 7. The failed MOS tube was checked by a stereo microscope. It was found that the fracture surface was clean and free of impurities, showing a typical form of fatigue fracture (Figure 8).In order to verify the mechanism of power failure, the power supply was inspected carefully. Cracks were also identified at multiple welding points of the power supply board and the control board, as shown in Figure 9.

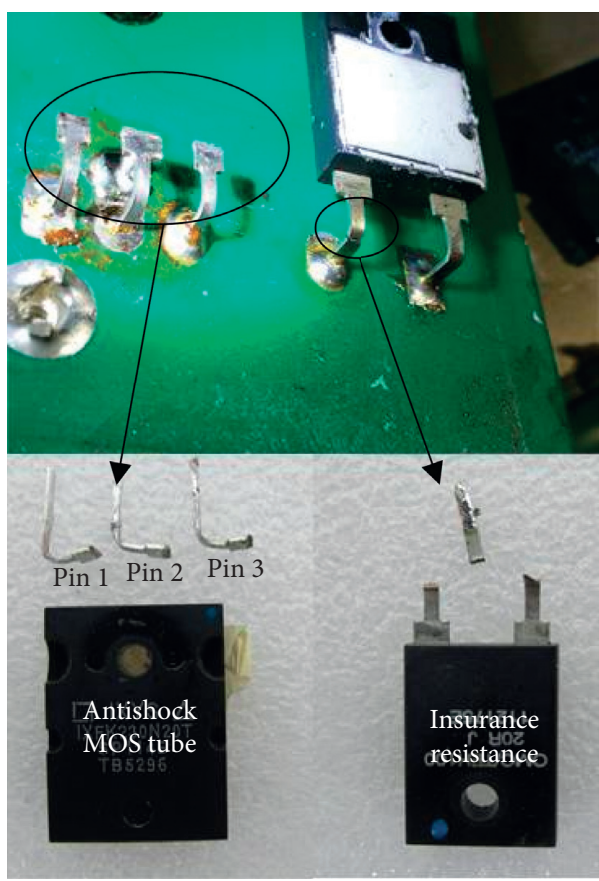

FIgURE 7: Fracture macromorphology of the semiconductor tube.

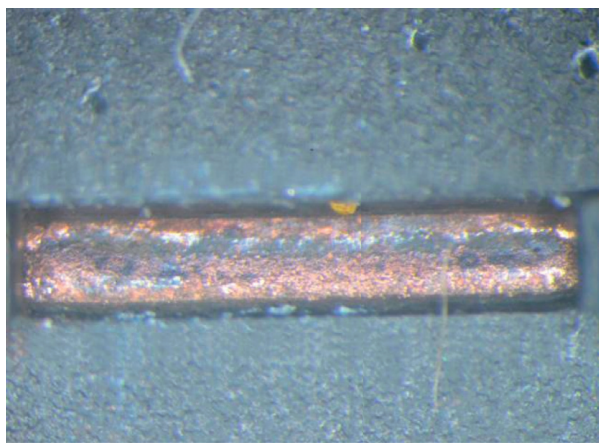

FIGURE 8: Fracture morphology of the pin for the semiconductor tube.

3.2. Failure Analysis. SEM microstructure observations of the fracture of the antishock MOS tube were carried out. The results show that Pin 1 and Pin 3 are similar, showing a near dimple-like fracture, and Pin 2 displays a fluvial fracture. Parts of the fracture of Pin 1 and Pin 3 have microcracks, which are likely to be caused by the crack extension. At the pin fracture, there is a spherical or molten structure which is caused by tip discharge after the pin breaks. However, a typical dimple-like fracture can still be seen from Figure 10(a). The dimple is in the same direction overall, showing a parabolic shape. The convex crack appears in the form of shear dimples or equiaxial tearing dimples, which are the combined effects of tensile stress and shear stress. This is caused by the random vibration of the array power supply. Therefore, the fracture of the MOS tubes is due to overstress. The formation of the fluvial fracture in Figure 10(b) can be explained as follows: Pin 2 was broken prior to Pin 1 and Pin 3 during vibration. At this point, the array power supply was still working, causing the contact 

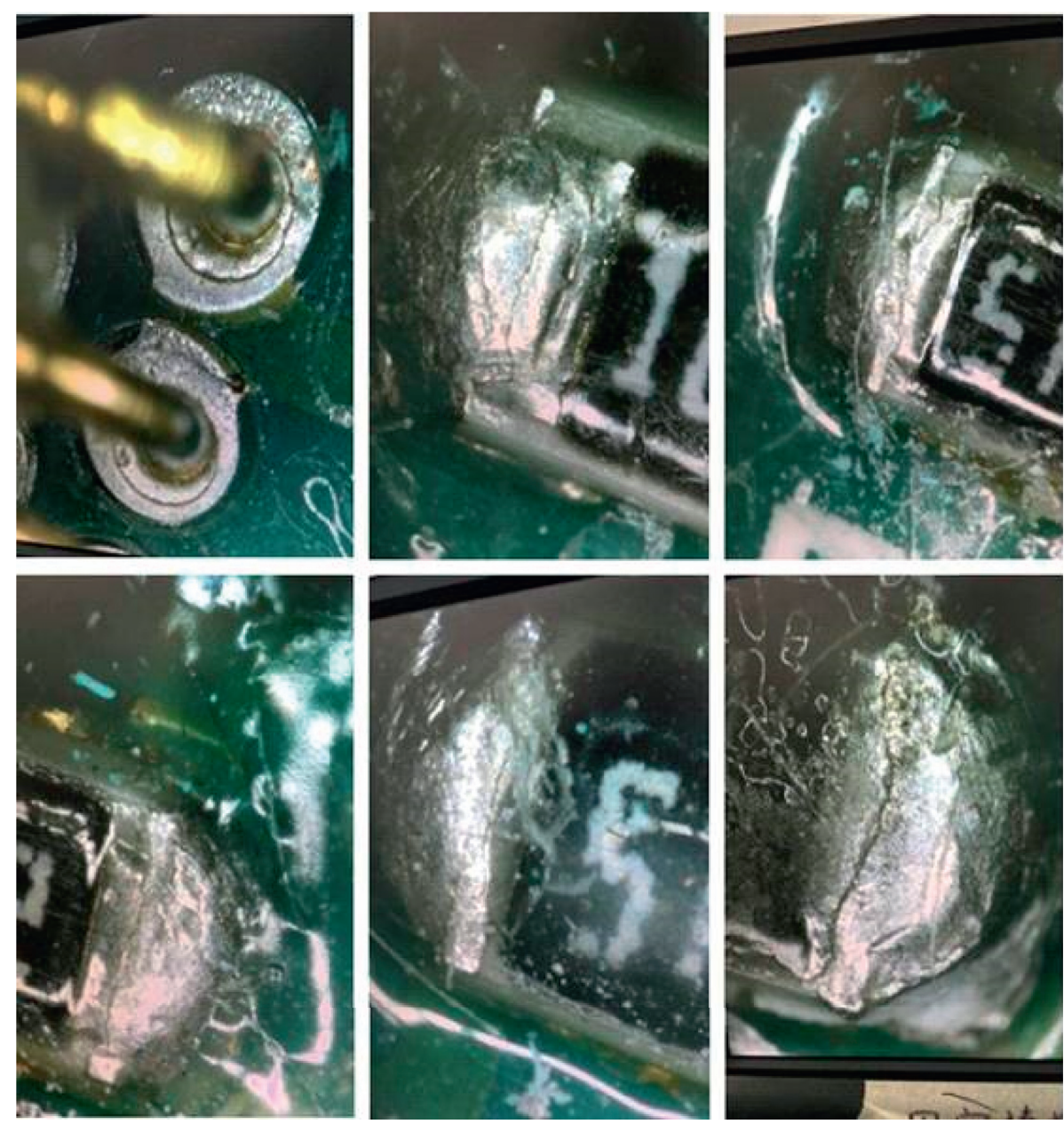

Figure 9: Macromorphology of the welding crack.

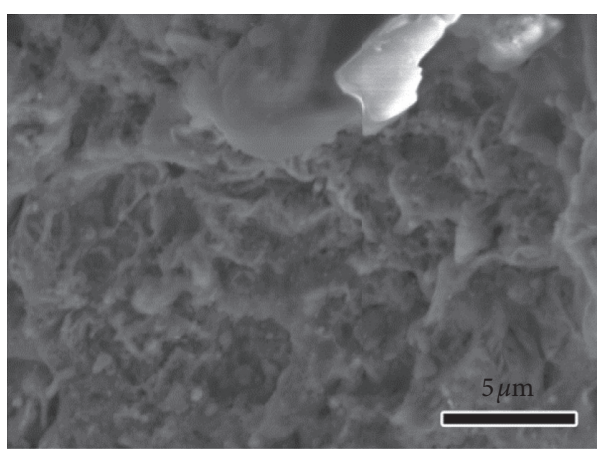

(a)

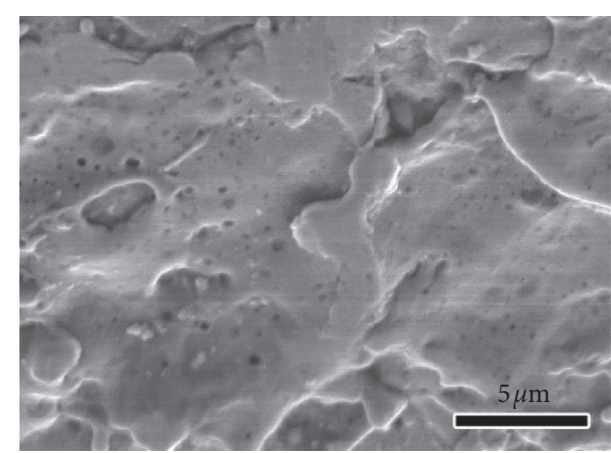

(b)

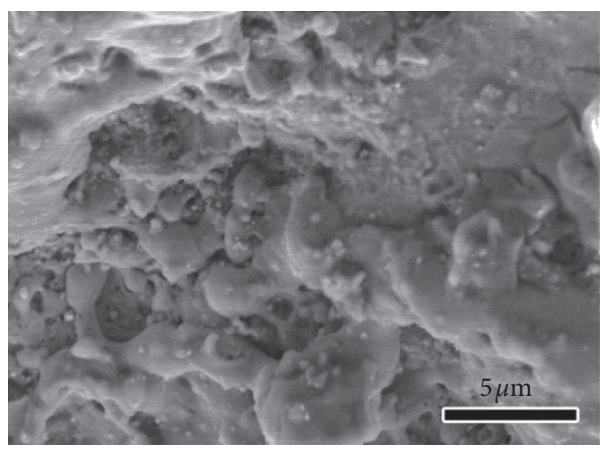

(c)

FIgUre 10: Micrographs of fracture surfaces of the pins of the antishock MOS tube: (a) Pin 1, (b) Pin 2, and (c) Pin 3. 
resistance at the fracture to increase, and then tip discharge occurred at the tip of the fracture. The pin materials melted continuously, and thus the fluvial fracture was formed. Through the EDS analysis (Table 1) of the three pins in Figure 10, it was obvious that no other impurity elements were found at the dimple fracture, the spherical particles, and the fluvial fracture. The surface of Pin 2 was covered with a layer of copper due to discharge fusion, which led to increased levels of copper, indicating the correctness of the above analysis.

SEM microscopic morphological observations of the fractured resistor tubes revealed that the entire pin surface has a typical equiaxial dimple structure (see Figure 11), which means the fracture was mainly caused by tensile stress. The spherical substances found in some areas of the fracture were the result of material fusion caused by tip discharge after the pin breaks. However, this fracture had few spheroids and was typically ductile. This shows that after the three pins of antishock MOS tube were fractured, without nearby support, the stress for the pin of the resistor tube was further concentrated here and caused a fracture.

Corrosion at welding points can also cause fractures at welding seams due to stress concentration [44-47]. To confirm the relationship between pin fracture and corrosion, the MOS tube and resistor tube were sealed to prepare a metallographic sample, and SEM observations were performed. The results are shown in Figure 12. There are only a few microcracks at the fracture of Pin 2 of the MOS tube, which were caused by vibration. There was no trace of corrosion on the substrate. After further observation of the pin, the coating was found to be intact without any corrosion.

The welding cracks of the power controlling board terminal are analyzed as an example here. From the cross section shown in Figure 13, it can be seen that the cracks all extend from the welding surface of the terminal to that of the printed board. Two cracks are found at the welding seam on one side of the board: one extends along the solder to the inside of the welding joint; the other extends to the weld interface after it reaches the welding joint of the solder and the printed board. Similar to the brittle fracture of ceramics, the cracks are relatively flat, which indicates that the fracture occurs in an instant without deformation. The hollow as well as the crack are found at the welding seam on the other side. The crack starts from the hollow and, after continuing for a certain distance, enters the weld interface.

From Figure 14, a partial view of the welding seam in Figure 13, we know that the fractures at the welding points are mainly transgranular, which means that brittle fracture occurs because the vibration stress here is too great. The welding seam extends from the solder to the weld interface of the printed board. Near the weld interface, the cracks are mainly found between the welding seam and the intermetallic compound (IMC) of the PCB pad. The IMC (Figure 14(c)) of the weld interface crack at A in Figure 13 is about $0.9 \mu \mathrm{m}$ thick, slightly smaller than that of the cross section of the wellwelded interface at B (Figure 14(d)) (about $1.2 \mu \mathrm{m}$ ). This shows that the IMC strength of the cross section is greater than that of the solder substrate. However, in the case of poor welding, a weak area will be formed at the IMC of the
TABLE 1: EDS test results of three locations of the antishock MOS tube.

\begin{tabular}{lccccccc}
\hline Location & Element & $\mathrm{C}$ & $\mathrm{O}$ & $\mathrm{Cu}$ & $\mathrm{Al}$ & $\mathrm{Si}$ & $\mathrm{k}$ \\
\hline Pin 1 & $\mathrm{Wt} \%$ & 27.29 & 7.83 & 55.53 & 0.98 & 6.43 & 1.94 \\
Pin 2 & $\mathrm{Wt} \%$ & 12.15 & 3.29 & 80.59 & 0.98 & 1.89 & 1.1 \\
Pin 3 & $\mathrm{Wt} \%$ & 23.87 & 7.38 & 60.34 & 1.48 & 5.61 & 1.32 \\
\hline
\end{tabular}

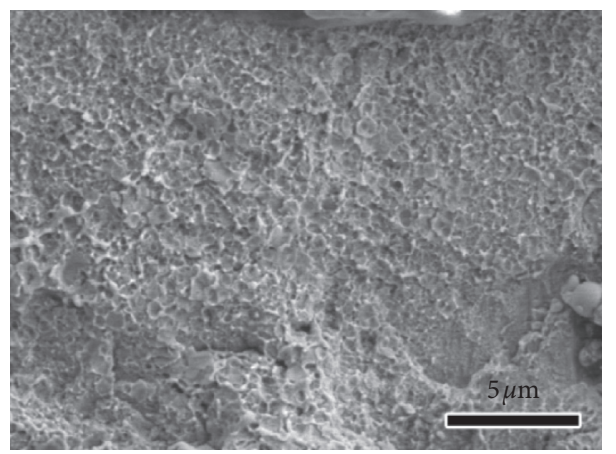

FIGURE 11: Micrographs of fracture surface of the pin of the resistor tube.

interface, which not only changes the direction of the crack extension but also accelerates the crack propagation.

From the above analysis, it can be seen that the fractures of Pin 1 and Pin 3 are dimple-shaped, but there are plenty of spheroids caused by multiple tip discharges. The fracture of Pin 2 is fluvial, which is caused by the fusions of the pin materials as a result of repeated postfracture discharges. Therefore, it can be estimated that the fracture of Pin 2 preceded that of Pin 1 and Pin 3. Fractures of the antishock MOS tubes reduce the strength and stiffness of the entire printed board. Fracture of the resistor tube was caused due to an excessive stress. Through observations, we find that there are only a few microcracks of the pin fracture, without any trace of corrosion on the substrate, and that coatings at other locations are also intact without any corrosion. Therefore, the fracture of field effect pins has nothing to do with corrosion but is a result of overstress during vibration. As vibration continues, the magnitude keeps increasing, causing multiple fractures at the welding points of the power printed board. The visible cracks on the welding point surface extend to the inside, and the fractures are mainly transgranular.

\section{Optimization Design and Simulation Analysis}

In view of the problems in the above vibration, it needs to be improved from the perspective of structure and process optimization. To optimize the design of the power supply, we should take advantage of the buffer effect of the wire in $\Omega$ welding to increase the stiffness, overcome the deformation caused by the soft connection between the pin and the printed board, and reduce the stress on the printed board during vibration. This can effectively avoid the rigid connection vibration fracture of pins for semiconductor. 


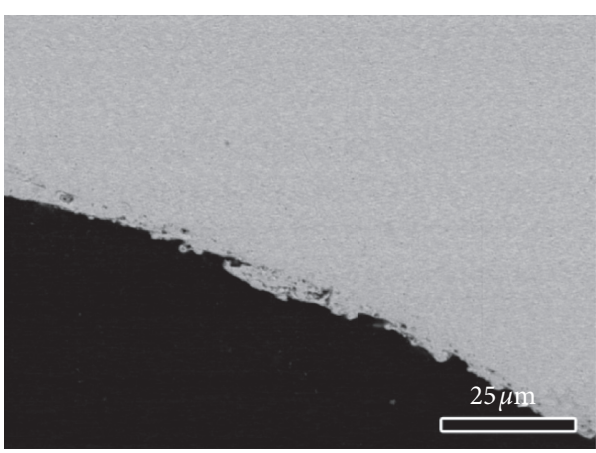

(a)

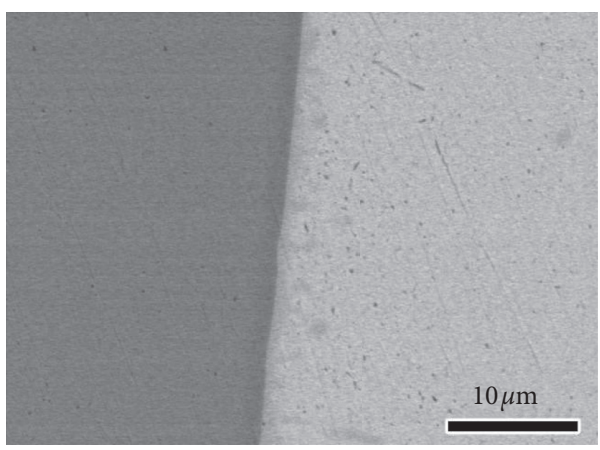

(c)

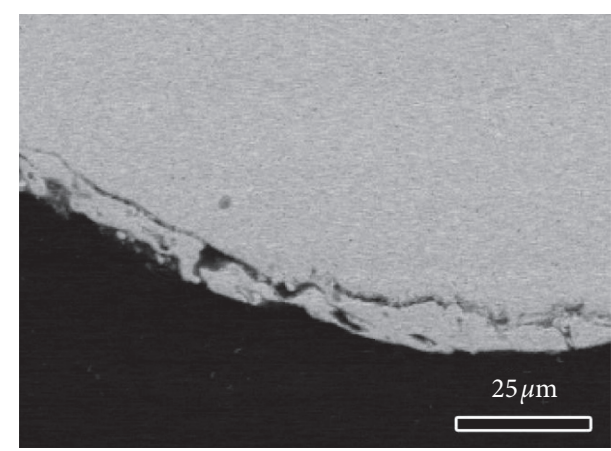

(b)

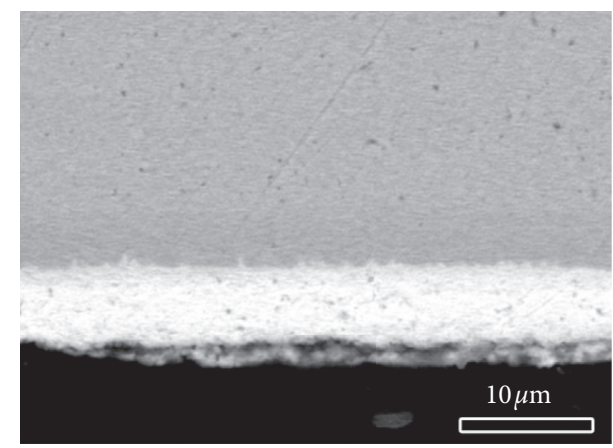

(d)

FIGURE 12: Cross-sectional SEM micrograph of the weld of antishock MOS tube: Pin 1 (a), Pin 2 (b), Pin 3 (c), and resistor tube (d).

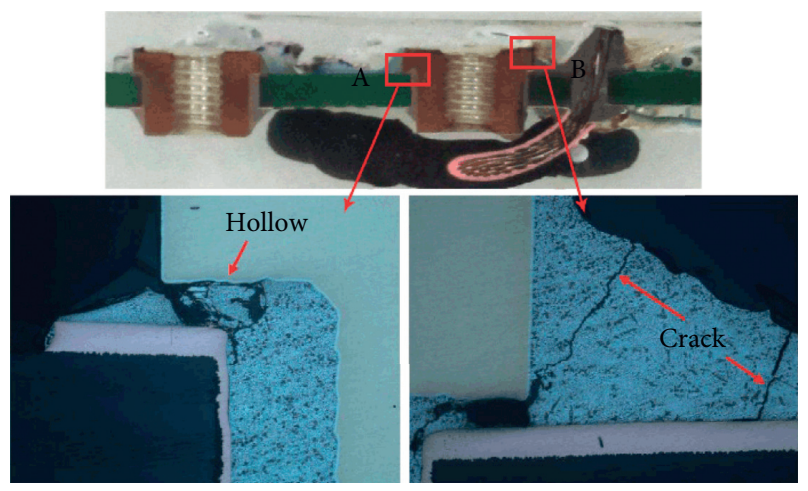

FIGURE 13: SEM micrograph of the cracks on the power control board terminal.

To further ensure the strength, the welding points of PCB devices were reinforced, as shown in Figure 15(a). The shell was also reinforced to increase its stiffness and reduce the transmissibility between the shell and the printed board, as shown in Figure 15(b).

On the basis of the above fracture analysis and design optimization, a simulation study was conducted. To ensure accuracy of the simulation results, a simulation evaluation system was proposed based on the high-confidence model. First, the simulation model and boundary conditions were modified with numerous tests to improve accuracy. The simulation results after modification were compared with themselves which were tested again to ensure simulation accuracy. The results are shown in Table 2 . The verification was based on the power controlling board, and both the test and simulation inputs were $1 \mathrm{~g}$. It was found that before optimization, the high-frequency response amplification at the test point of the controlling board was obvious, with the total RMS value being approximately $8.4 \mathrm{~g}$, or around 8.4 times larger. Through the test modification, the simulation result was amplified and was 8.9 times larger than the excitation. After the design optimization, the total RMS value of the measured data at the test point of the controlling board was enlarged by approximately 4.5 times. Through test modification, the simulation result was amplified and was 4.8 times larger than the excitation. Through the test and simulation comparison before and after optimization, the following conclusions can be drawn: (1) through structural optimization and other measures, the high frequency of the controlling board is reduced by more than 46\%; (2) the damage caused by random vibration can be controlled by structural optimization; (3) the accuracy of the simulation evaluation system of this high-confidence model is within $10 \%$.

With the vibration spectrum of the functional test as an input, a mechanical simulation analysis was performed for the power control board before design optimization. As could be seen from the simulation results in Figure 16(a), the maximum stress at the semiconductor tube pin was higher than $200 \mathrm{MPa}$, while the tensile strength of the pin material (fine copper) was $196 \mathrm{MPa}$. The pin of tube was fractured when the maximum stress was larger than the tensile strength. This is mainly due to the large vibration magnitude, the heavy weight of devices on the printed board (the total 


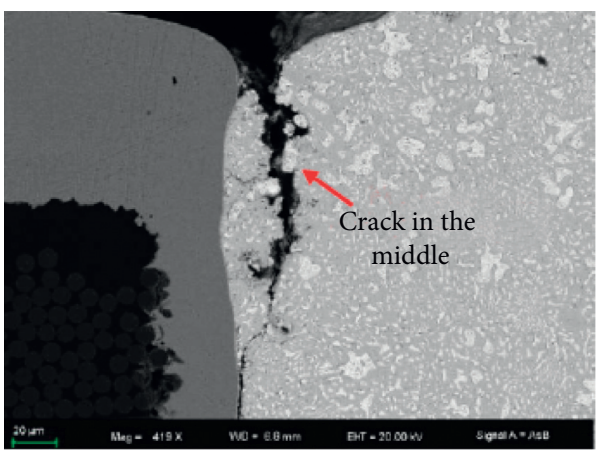

(a)

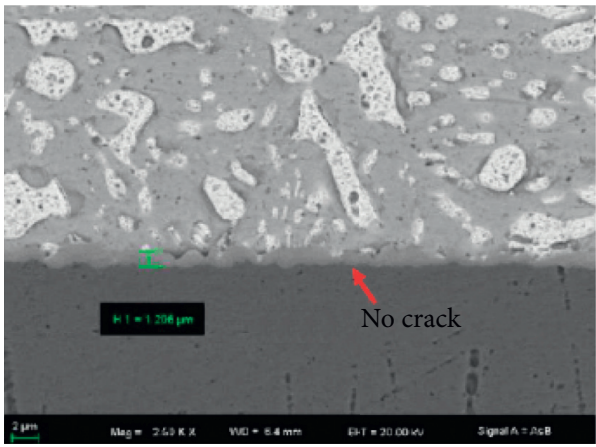

(c)

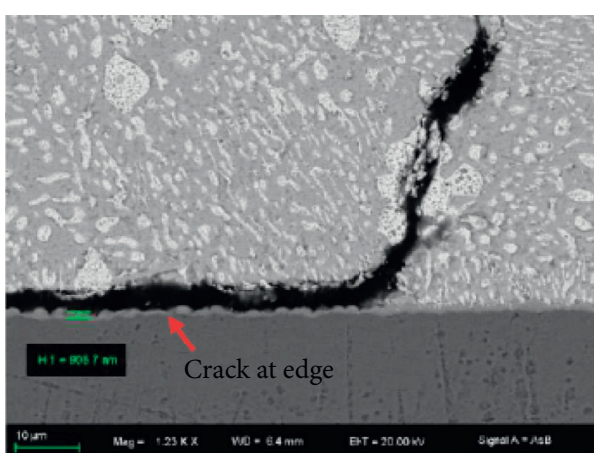

(b)

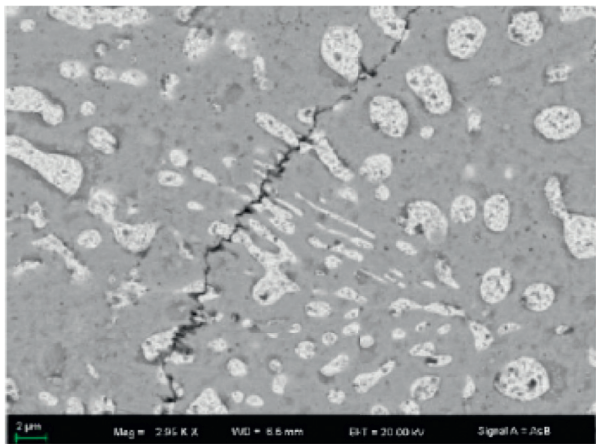

(d)

FIGURE 14: Partial view of the cracks on power control board terminal: (a) crack in the middle of the solder, (b) crack at the interface, (c) no crack at the interface, and (d) partial enlarged view of the solder crack.

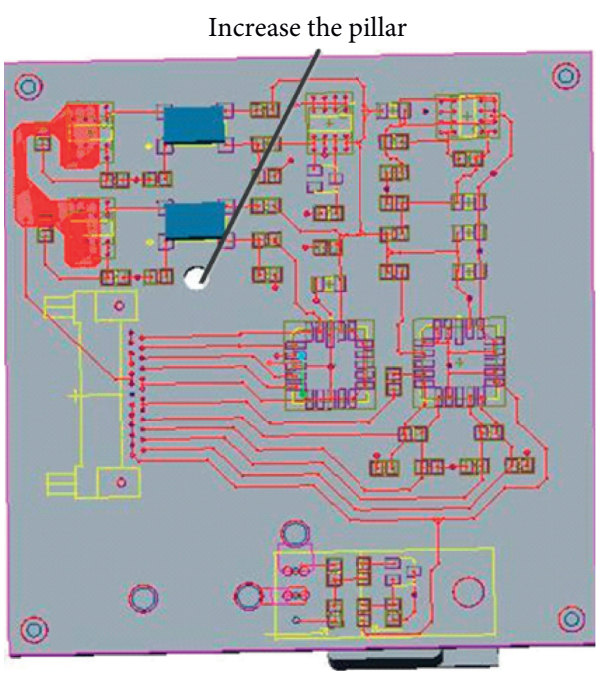

(a)

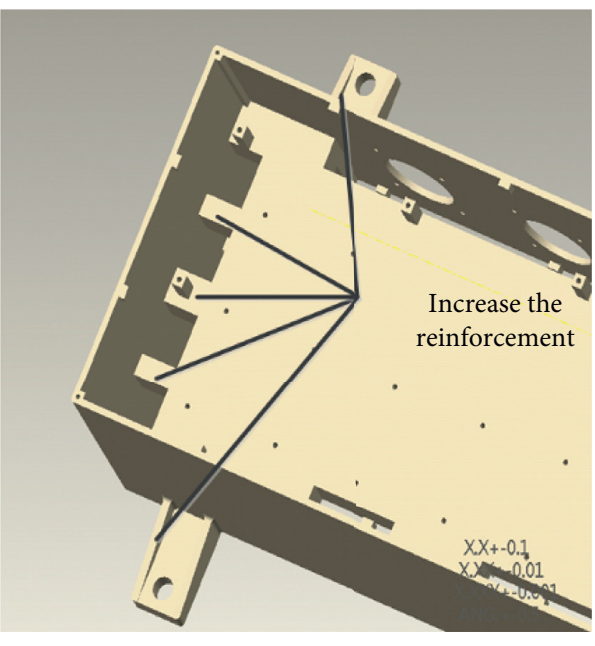

(b)

FiguRE 15: Diagram of power supply reinforcement: (a) printed board reinforcement, and (b) shell reinforcement.

TABLE 2: Comparison between simulation and test results based on the high-confidence evaluation system (unit: $g$ ).

\begin{tabular}{lcc}
\hline State & Simulation result & Test value \\
\hline Initial state & 8.9 & 8.4 \\
Optimal poststate & 4.8 & 4.5 \\
\hline
\end{tabular}

weight of the three capacitors is $253.5 \mathrm{~g}$ ), the unstable structure, and the overlarge response during vibration. The fractures were mostly ductile, which was consistent with the fracture analysis above. From the stress rephotographed after optimization shown in Figure 16(b), it could be seen that the maximum stress was reduced to less than $50 \mathrm{MPa}$, 
Equivalent stress

Type: equivalent stress

Scale factor value: 3 Sigma

Probability: 99.73\%

Unit: Pa

Time: 0

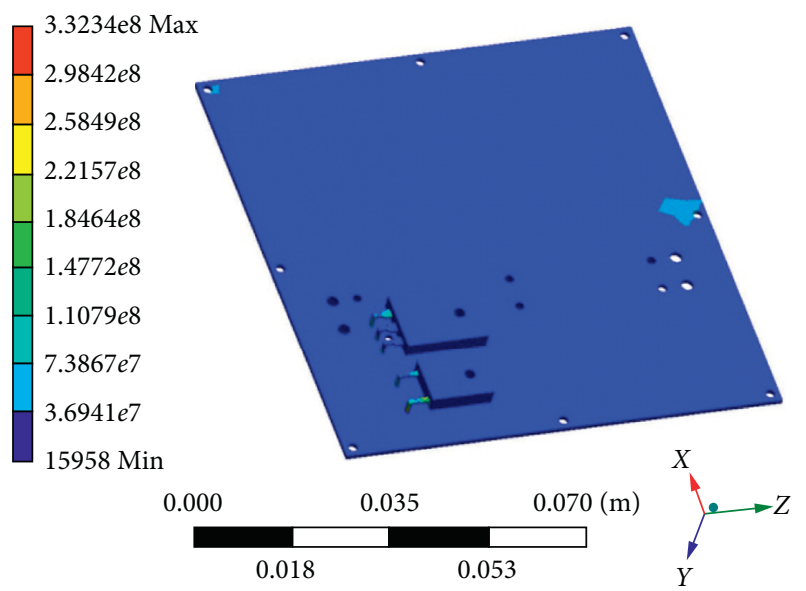

(a)
Equivalent stress

Type: equivalent stress

Scale factor value: 3 Sigma

Probability: $99.73 \%$

Unit: Pa

Time: 0

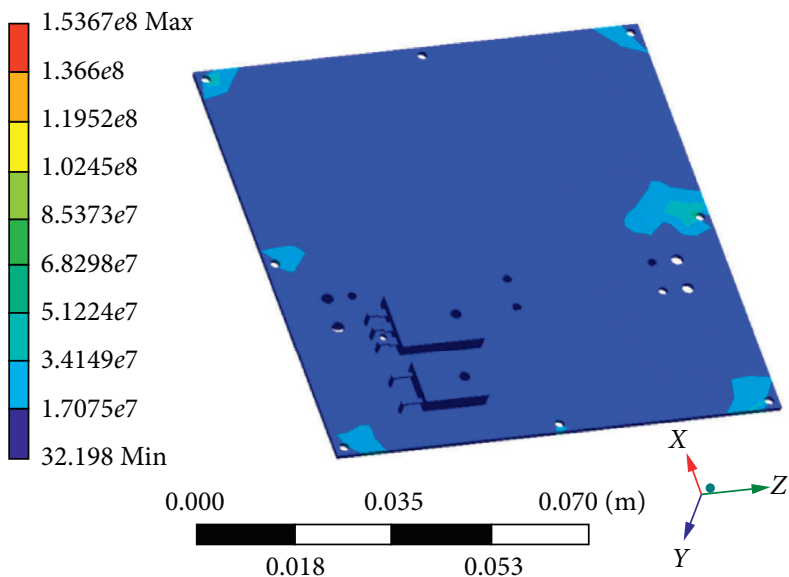

(b)

FIgURE 16: Comparative analysis of semiconductor tube stress simulation: (a) before optimization and (b) after optimization.

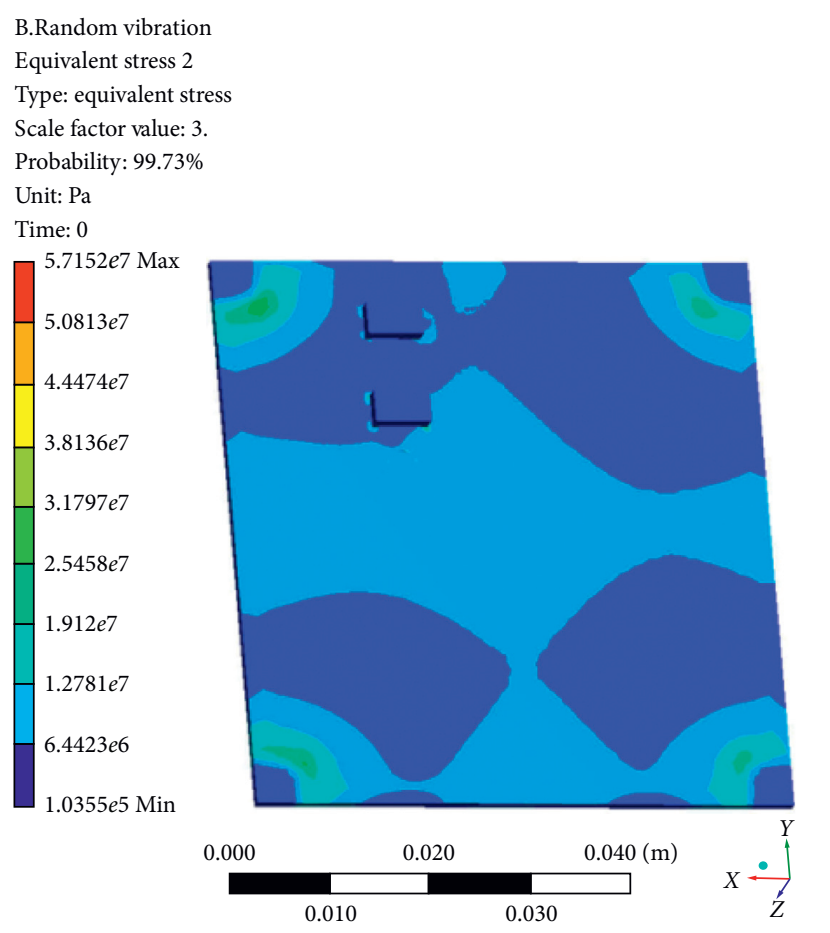

(a)

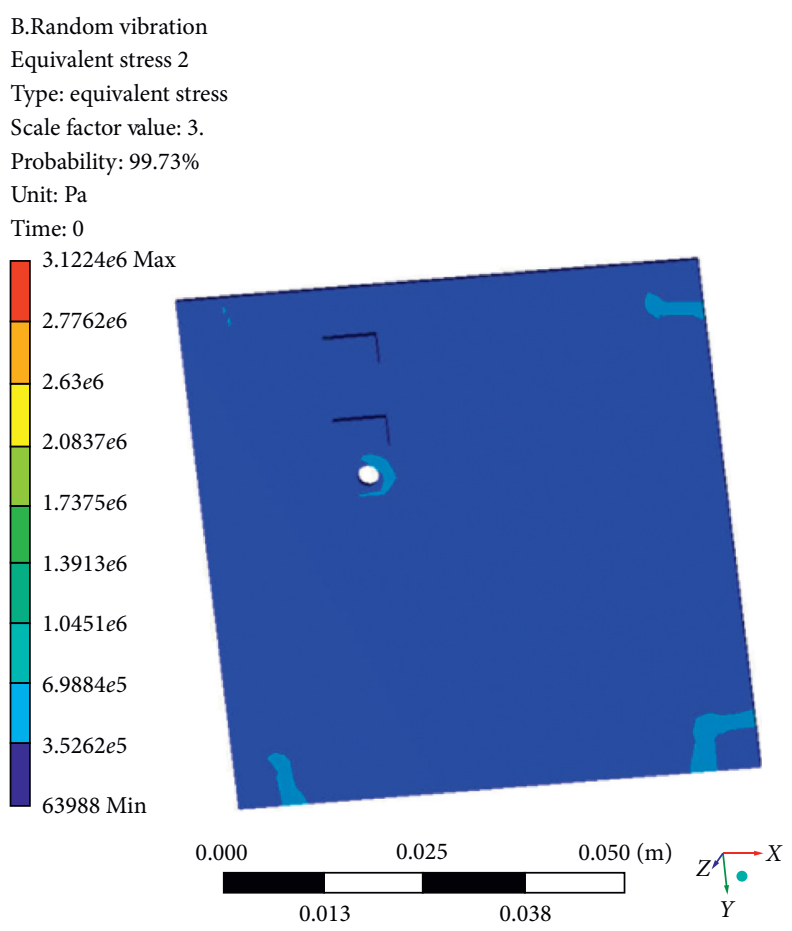

(b)

FIGURE 17: Comparative analysis of stress simulation at the welding point of the semiconductor tube (a) before optimization and (b) after optimization.

much lower than the tensile strength of the material (196 $\mathrm{MPa})$. The maximum stress was no longer on the pin; in other words, the tube pins will not fracture.

The type of solder used to weld the semiconductor tube device was $\mathrm{Sn}-\mathrm{Pb}(63 \mathrm{Sn} 37 \mathrm{~Pb})$ whose tensile strength being
$30 \mathrm{MPa}$. Figure 17 shows that the maximum stress at the welding points was $57.1 \mathrm{MPa}$, much larger than the tensile strength of the $\mathrm{Sn}-\mathrm{Pb}$ solder, thus causing brittle fracture at the welding points due to excessive stress. After optimization, the stress at the welding points drops to less than 
$5 \mathrm{MPa}$, much lower than the tensile strength of the tin solder $(30 \mathrm{MPa})$. The array power supply passed the test without any fractures or cracks which proved the rationality of the optimization design.

\section{Conclusions}

(1) During random vibration, the stress concentration of the antishock MOS tube and the resistor exceeded the yield strength by about $20 \%$ and the fractures were mostly dimple ones, along with fluvial fractures caused by tip discharge as well as microspherical structures.

(2) The fractures at the welding seams of relevant devices were mostly transgranular, mainly because the stress at the seams was much larger than the strength of tin solder, resulting in brittle fractures.

(3) To tackle the fracture problem, the array power supply was optimized from three aspects and a random vibration test had been conducted successfully to avoid fractures and microcracks.

(4) The fracture analysis results were verified by actual tests and simulations, which justify the fracture analysis in the paper.

\section{Data Availability}

All data generated or analyzed during this study are included in this article.

\section{Conflicts of Interest}

The authors declare no conflicts of interest.

\section{Authors' Contributions}

C.-r. W. was involved in conceptualization and methodology; H.-h. W. performed formal analysis; H.-h. W., C.-r. W., and H.-h. W. performed investigation; H.-h.W. was responsible for resources; L.-n.T. was involved in writing and original draft preparation; C.-r.W. wrote, reviewed, and edited the manuscript; L.-n.T. supervised the study and was involved in project administration.

\section{Acknowledgments}

This work was supported by the "National Natural Science Foundation of China" (no. 51601117) and "National Key Laboratory of Science and Technology on Helicopter Transmission" (no. HTL-O-19G09).

\section{References}

[1] M. Santoro, U. Wegmuller, and J. I. H. Askne, "Signatures of ERS-Envisat interferometric SAR coherence and phase of short vegetation: an analysis in the case of maize fields," IEEE Transactions on Geoscience and Remote Sensing, vol. 48, no. 4, pp. 1702-1713, 2010.

[2] P. Zhou, P. Ren, and Y. S. Dai, "A wide-beam scanning mode for near-space passive SARs," International Journal of
Antennas and Propagation, vol. 2012, Article ID 930137, 7 pages, 2012.

[3] E. Kiraci, P. Franciosa, G. A. Turley, A. Olifent, A. Attridge, and M. A. Williams, "Moving towards in-line metrology: evaluation of a laser radar system for in-line dimensional inspection for automotive assembly systems," The International Journal of Advanced Manufacturing Technology, vol. 91, no. 1-4, pp. 69-78, 2017.

[4] C. Dong, C. Liu, Q. Wang, and L. Gong, "Switched adaptive active disturbance rejection control of variable structure near space vehicles based on adaptive dynamic programming," Chinese Journal of Aeronautics, vol. 32, no. 7, pp. 1684-1694, 2019.

[5] W. Zuo, Y. Pi, and R. Min, "An extended frequency scaling algorithm for high squint spotlight airborne sar," Progress in Electromagnetics Research, vol. 138, pp. 41-63, 2013.

[6] R. D. Yan, L. M. Jackson, and S. J. Dunnett, "Automated guided vehicle mission reliability modelling using a combined fault tree and Petri net approach," The International Journal of Advanced Manufacturing Technology, vol. 92, no. 5-8, pp. 1825-1837, 2017.

[7] T. Owerko and P. Kuras, "Effective processing of radar data for bridge damage detection," Shock and Vibration, vol. 2019, Article ID 2621092, 13 pages, 2019.

[8] Q. Xin, Z. Wang, Z. H. Jiang, and H. G. Kan, "A miniature HRWS SAR concept for near-space vehicles," in Proceedings of the 13th International Radar Symposium, Warsaw, Poland, May 2012.

[9] M. Shimada and T. Ohtaki, "Generating large-scale highquality SAR mosaic datasets: application to PALSAR data for global monitoring," IEEE Journal of Selected Topics in Applied Earth Observations and Remote Sensing, vol. 3, no. 4, pp. 637-656, 2010.

[10] Y. Dong, R. Tao, and S. Zhou, "Joint STAP-WVD based SAR slowly moving target detection and imaging," in Proceedings of the IEEE International Radar Conference, Alexandria, USA, May 2000.

[11] C. Zhu, W.-Q. Wang, H. Chen, and H. C. So, "Impaired sensor diagnosis, beamforming, and DOA estimation with difference co-array processing," IEEE Sensors Journal, vol. 15, no. 7, pp. 3773-3780, 2015.

[12] W.-Q. Wang, "Near-space vehicle-borne SAR with reflector antenna for high-resolution and wide-swath remote sensing," IEEE Transactions on Geoscience and Remote Sensing, vol. 50, no. 2, pp. 338-348, 2012.

[13] L. Feng, H. P. Xu, and C. S. Li, "Data simulation for near-space formation flying SAR," Chinese Journal of Radio, vol. 26, no. 4, pp. 654-660, 2011.

[14] X. F. Xia, L. H. Liu, S. B. Ye, H. F. Guan, and G. Y. Fang, “A novel subnanosecond monocycle pulse generator for UWB radar applications," Journal of Sensors, vol. 2014, Article ID 150549, 4 pages, 2014.

[15] K. W. Shao, C. R. Wang, and H. Xiao, "Structure design of a array power supply for phased-array radar," Machinery \& Electronics, vol. 4, pp. 18-22, 2015.

[16] Y. L. Zhao, C. P. Li, M. Y. Zhao, S. M. Xu, H. Gao, and L. Song, "Model design on emergency power supply of electric vehicle," Mathematical Problems in Engineering, vol. 2017, Article ID 9697051, 6 pages, 2017.

[17] Q. Yang and M. Chen, "Adaptive neural prescribed performance tracking control for near space vehicles with input nonlinearity," Neurocomputing, vol. 174, pp. 780-789, 2016. 
[18] R. Hu, Z. Wu, Z. Wu, X. Wang, and Z. Tian, "Aerodynamic map for soft and hard hypersonic level flight in near space," Acta Mechanica Sinica, vol. 25, no. 4, pp. 571-575, 2009.

[19] J. J. Bertin and R. M. Cummings, "Fifty years of hypersonics: where we've been, where we're going," Progress in Aerospace Sciences, vol. 39, no. 6-7, pp. 511-536, 2003.

[20] I. Elishakoff, M. Baruch, L. Zhu, and R. Caimi, "Random vibration of space shuttle weather protection systems," Shock and Vibration, vol. 2, no. 2, pp. 111-118, 1995.

[21] S. T. Zhou, Y. J. Chiu, and I. H. Lin, "The parameters optimizing design of double suspension arm torsion bar in the electric sight-seeing car by random vibration analyzing method," Shock and Vibration, vol. 2017, Article ID 8153756, 9 pages, 2017.

[22] T. S. Edwards, "Power delivered to mechanical systems by random vibrations," Shock and Vibration, vol. 16, no. 3, pp. 261-271, 2009.

[23] R. G. Lambert, "Accelerated test (time-compressed) methodologies for elastomeric isolators under random vibration," in Proceedings of the 40th Annual Technical Meeting of the Institute-of-Environmental-Sciences-Education for Technical Excellence, Chicago, IL, USA, May 1994.

[24] Y. A. Dzenis and I. Saunders, "On the possibility of discrimination of mixed mode fatigue fracture mechanisms in adhesive composite joints by advanced acoustic emission analysis," International Journal of Fracture, vol. 117, no. 4, pp. 23-28, 2012.

[25] H. Zhang and P. Qiao, "A state-based peridynamic model for quantitative fracture analysis," International Journal of Fracture, vol. 211, no. 1-2, pp. 217-235, 2018.

[26] C. Jiang, J. W. Li, B. Y. Ni, and T. Fang, "Some significant improvements for interval process model and non-random vibration analysis method," Computer Methods in Applied Mechanics and Engineering, vol. 357, Article ID 112565, 48 pages, 2019.

[27] L. Chen, H. Zhu, and J. Q. Sun, "Novel method for random vibration analysis of single-degree-of-freedom vibroimpact systems with bilateral barriers," Applied Mathematics and Mechanics, vol. 40, no. 12, pp. 1759-1776, 2019.

[28] M. A. Gharaibeh and J. M. Pitarresi, "Random vibration fatigue life analysis of electronic packages by analytical solutions and Taguchi method," Microelectronics Reliability, vol. 102, Article ID 113475, 9 pages, 2019.

[29] Y. Jiang, G. J. Yun, L. Zhao, and J. Y. Tao, "Experimental design and validation of an accelerated random vibration fatigue testing methodology," Shock and Vibration, vol. 2015, Article ID 147871, 13 pages, 2015.

[30] T. Liu, C. R. Li, Q. Cheng, and L. Qiao, "Random vibration fatigue analysis for a structure," Journal of Vibration and Shock, vol. 32, no. 21, pp. 97-102, 2013.

[31] A. Pothula, A. Gupta, and G. R. Kathawate, "Fatigue failure in random vibration and accelerated testing," Journal of $\mathrm{Vi}$ bration and Control, vol. 18, no. 5, pp. 1199-1206, 2012.

[32] X. L. Liu, X. Chen, X. Q. Hou, and C. H. Tao, "Damage and fracture speciality of FGH95 powder superalloy," Rare Metal Materials and Engineering, vol. 38, no. 7, pp. 1179-1184, 2009.

[33] G. Chen, C. Ren, and X. Yang, "Finite element simulation of high-speed machining of titanium alloy (Ti-6Al-4V) based on ductile failure model," The International Journal of Advanced Manufacturing Technology, vol. 6, no. 9-12, pp. 1027-1038, 2011.

[34] F. Lu, D. Kennedy, F. W. Williams, and J. H. Lin, "Nonstationary random vibration of FE structures subjected to moving loads," Shock and Vibration, vol. 16, no. 3, pp. 291-305, 2009.

[35] Z. P. Zeng, Z. W. Yu, Y. G. . Zhao, W. T. Xu, L. K. Chen, and P. Lou, "Numerical simulation of vertical random vibration of train-slab track-bridge interaction system by PEM," Shock and Vibration, vol. 2014, Article ID 304219, 21 pages, 2014.

[36] P. B. Li, Y. J. Li, and H. G. Lin, "Numerical simulation and experimental researches on the vibration-acoustic coupled property of an aircraft model under strong reverberation noise," Journal of Vibration and Shock, vol. 23, no. 17, pp. 2756-2766, 2017.

[37] J. Q. Wang, X. Shen, and J. F. Li, “A design and experimental research of a frequency tunable vibration isolator based on SMA," Journal of Vibration and Shock, vol. 36, no. 20, pp. 59-63, 2017.

[38] Y. Y. Li, G. P. Chen, and K. Wang, "Optimization design for dynamic anti-resonance isolators of helicopters' rotor/fuselage," Journal of Vibration and Shock, vol. 35, no. 15, pp. 115-122, 2016.

[39] G. X. Dong, Q. Li, and X. N. Zhang, "Vibration attenuation using a nonlinear dynamic vibration absorber with negative stiffness," International Journal of Applied Electromagnetics and Mechanics, vol. 1, pp. 1-12, 2018.

[40] H. Harmoko, F. F. Yap, N. Vahdati, and C. Li, "Design and analysis of shock and random vibration isolation of operating hard disk drive in harsh environment," Shock and Vibration, vol. 16, no. 2, pp. 143-154, 2009.

[41] Z. Y. Du, S. P. Shi, and Z. T. Liang, "Vibration numerical analysis of the transmitter pedestal of an airborne radar," Electro-Mechanical Engineering, vol. 31, no. 4, pp. 1-4, 2015.

[42] J. B. Roberts and P. D. Spanos, "Stochastic averaging: an approximate method of solving random vibration problems," International Journal of Non-Linear Mechanics, vol. 21, no. 2, pp. 111-134, 1986.

[43] D. S. Spanos, Vibration Analysis for Electronic Equipment, John Wiley \& Sons, New York, NY, USA, 3rd edition, 2000.

[44] D. Q. Peng, S. L. Hu, and P. Z. Zhang, "Stress corrosion cracking behavior of reactor components welded 304L stainless steel in deoxygenized and chloride ions solution," Rare Metal Materials and Engineering, vol. 45, no. 7, pp. 1771-1776, 2016.

[45] D. D. Meo, C. Diyaroglu, N. Zhu et al., "Modelling of stresscorrosion cracking by using peridynamics," International Journal of Hydrogen Energy, vol. 41, no. 15, pp. 6593-6609, 2016.

[46] P. Livieri and P. Lazzarin, "Fatigue strength of steel and aluminium welded joints based on generalised stress intensity factors and local strain energy values," International Journal of Fracture, vol. 133, no. 3, pp. 247-276, 2005.

[47] T. Shoji, Y. Sato, D. Minkov et al., "Development of novel NDE techniques and their significance in the COE program on the physics and chemistry of fracture and failure prevention," International Journal of Applied Electromagnetics and Mechanics, vol. 14, no. 1-4, pp. 467-476, 2002. 